\title{
Social Work and the Green Economy
}

\author{
Bret Alan Weber
}

\begin{abstract}
This is an ethnographic account of a social worker's efforts to create a local "Energy Alliance" to help moderate-income residents reduce energy costs in a small, urban, northern plains community in the United States. Additionally, the initiative would help create jobs, increase energy efficiency, and reduce carbon outputs. While the project met with mixed results, lessons learned are relevant to the emergent intersections of community practice, sustainable community development (economic and social), and social work. The benefits of social work education and experience to this work are highlighted, as are the challenges inherent in planning and implementing green community development.
\end{abstract}

Keywords: Community economic and social development, energy alliance, environmental social work, sustainability, green economy, community practice

\section{INTRODUCTION}

This article is an ethnographic exploration of a social worker's efforts to create a local "Energy Alliance." The purpose of this community project was to help moderateincome residents reduce energy costs, while increasing energy efficiency in a small, urban, northern plains community in the United States. These efforts sought local benefits for the immediate community while helping to make some small contribution toward reducing carbon outputs that affect climate change. It was also an effort to engage the perspectives and skill set of social work with the challenges of the 'green economy.'

The volunteers who participated in this project were successful in creating a new organization within the city government and in procuring Energy Efficiency and Conservation Block Grants. However, the new program did not perform as well as was hoped in relation to providing economic relief for moderate-income families or spurring local economic development. Rubin and Sherraden's (2005) conceptualization of CESDOs (Community Economic and Social Development Organizations) is employed to illustrate key issues facing the Energy Alliance at its inception and over the longer term. Community practice models also provide insights into tasks, challenges, and practitioner roles.

This article is written in the spirit that mistakes and less-than-optimal outcomes also provide valuable lessons. It also highlights the strengths that social workers may bring to local "green" initiatives. This is fairly unknown territory for social workers in the United States, however, it is hoped that sharing this case example will offer relevant insights and encouragement to the growing number of social workers who consider global environmental sustainability to be relevant to social work practice.

Bret A. Weber, Ph.D., MSW, LCSW, is an Assistant Professor in the Department of Social Work at the University of North Dakota in Grand Forks, ND.

Copyright $(2012$ Advances in Social Work Vol. 13 No. 2 (Summer 2012), 391-407 


\section{THEORETICAL CONTEXT FOR THE PROJECT}

The author's active participation and leadership in this project were simultaneously grounded in the intersections of social work, environmental sustainability, and community and economic development work. First and foremost, social workers know that people need to be understood within the broad context of their environment. This person-in-environment perspective encompasses all the diverse aspects of social work practice and distinguishes it from other helping professions. However, especially in the United States, the term too often fails to consider the natural and physical environment. This is particularly unfortunate in the face of ongoing environmental and climatic shifts that disproportionately threaten vulnerable populations both around the globe and in the wealthiest nations. This is a matter of global concern that requires local solutions and is directly relevant to social work practice. Zapf (2009) noted that social workers "have been strangely silent" about issues related to the natural, physical environment and the related "serious threats to human well-being and continued existence" (p. 18).

Environmental sustainability is also a social justice issue. The wealthiest populations tend to be the greatest consumers and producers of the products and activities damaging to the global environment, yet the impoverished are most likely to suffer the consequences. For instance, the United States is the world's top emitter of carbon dioxide, but the cost of climate change is disproportionately borne by those least able to either afford the costs or recover from the effects. Extreme weather events between (1990-2009) as noted in the Global Climate Risk Index 2011 most seriously impacted "developing countries in the low-income or lower-middle income country group" (Harmling, 2010, p. 5). Indeed, as a result of climate change, tens of millions of Bangladeshis could be displaced by rising sea levels over the coming decades, and that nation's agriculture is already suffering from sanitization as rising sea levels contaminate the nation's delta regions (Chopra, 2009). Throughout the developing world, social workers tend to focus on social development and issues of sustainability directly related to environmental issues including population, food supplies, and disasters connected to natural devastation. However, in the United States, social workers are largely silent on environmental issues, even though they can make a significant difference by bringing their unique set of values, ethics, and skills to make a difference locally.

Rubin and Sherraden (2005) and their formulation of Community Economic and Social Develpoment (CESD) have offered a critical redefinition of traditional community economic development models that too-frequently had ignored social and economic justice implications, and posit the need for a "humane capitalism" that is holistic, focused on those who are left out of traditional economic development efforts to build and harnesses community assets in ways that result in both economic improvement and social change (p. 475). Innovation is a hallmark of CESD, which also positions it well as a framework for environmentally sustainable community development. Additionally, the use of community practice models also (Rothman, 2007; Weil \& Gamble, 2005) guide this work and this analysis. 


\section{EARLY GREEN ORGANIZING EFFORTS BY THE CITY}

This community project was undertaken in an area dominated by flat, flood-prone plains in a basin that drains into the arctic waters of the Hudson Bay. The area has little deciduous foliage to capture solar heat, cold winds that sweep across the plains from the Canadian Rockies, and arctic high pressure systems that produce frigid temperatures from October through March-low temperatures dip below $0^{\circ} \mathrm{F}$ fifty days per year. Residents burn a lot of fossil fuels to keep their homes warm during these notoriously cold winters.

Aware of the increasing financial costs for local citizens and the related global damage, the city's Mayor signed on to a national Sierra Club program with the somewhat ironic title of Cool Cities during the Spring of 2007. Since 2005, the Cool Cities' initiative has facilitated collaborations "to implement clean energy solutions that save money, create jobs, and help curb global warming” (Sierra Club, 2011). Within a few years, over one thousand cities and counties had joined the commitment to reduce their community's carbon footprint. Additionally, in announcing his decision the Mayor noted concerns in The United States Conference of Mayors' Energy and Environment Best Practices guide describing "America's vulnerability to an uncertain energy future," a policy environment that was "not sustainable" and references to national leadership that was either denying global warming or simply not acting on these broadly recognized concerns. The document noted "fortunately ... Mayors from across America are taking the lead" (U.S. Conference of Mayors, 2007).

Some of the volunteers who joined what came to be known as the Mayor's " $\mathrm{G}-3$ Environmental Initiative” in 2007 included a professor from the local university's Earth System Science and Policy department, along with the produce manager at the local food co-op who also happened to be one of the State's leading activists on behalf of energy and environmental issues. The effort was also joined by "a key author" of the Intergovernmental Panel on Climate Change (IPCC) report on climate change. His work had been part of the 2007 Nobel Peace Prize awarded jointly to former Vice President Al Gore and the IPCC for raising global awareness about the human impacts on the environment and climate. In a press release, he expressed the hope "that my grandchildren will not blame my generation for our stupidity of spending nature's capital while leaving the payments to them" (University of North Dakota, 2007). Altogether, the group eventually included some five dozen individuals including university professors, local activists, and various other community members and city officials (Bonzer, 2008).

Given the amount of talent assembled to work in this modestly-sized community, the work started in a spirit of great optimism. G-3 membership consisted of approximately three dozen individuals. A majority of these were university faculty, environmental activists (including a large number of students), and a few city employees. Official meetings began during the fall of 2007at a time when the author was teaching a class. Nonetheless, through e-mail and informal connections, it was clear that group members were passionate about the topic, and willing to volunteer their time to identify feasible tasks that could be accomplished by city government in partnership with other stakeholders. 
When I did begin attending meetings, the larger group had been meeting for about three month before I was able to come to my first meeting, yet I was surprised at how little had been accomplished. Beyond an enthusiastic report read by a student intern who had been assigned to the committee, not much else was accomplished at my first meeting.

The next meeting that I attended was for the policy sub-committee, a smaller group of six individuals, which included a veteran city council member and a senior aid to the mayor. The main decision made at that meeting was that each member would individually review a long list of programs and ideas from other cities around the region, and return with recommendations. The list was dominated by 'low-hanging fruit' ideas such as changing to more energy efficient lighting, coordinating the city's stoplights for more efficient traffic flows, and directives to get city employees to reduce their use of paper. For the most part, it was disappointing that these efforts had not already been implemented.

Four months into the effort, the G-3 Initiative and its subcommittees still seemed to be at the "brainstorming" stage; however, as a relative newcomer to the community, the effort afforded me an opportunity to develop relationships and mutual trust with community members and city staff, and an understanding of the city's political landscape and stakeholder interests.

An opportunity came in the form of an e-mail circulated by the president of the local chapter of the Sierra Club, containing a link to the Cambridge Energy Alliance (CEA), a group that was just forming in Cambridge, Massachusetts. The basic principles of the CEA were not particularly revolutionary, but they provided an outline of a program sufficiently simple in its concept to be taken on by a community practitioner with only limited training in environmental issues and limited technical and engineering knowledge. The idea also seemed well-suited to a medium-sized and fairly wellorganized community. It promised to simultaneously promote local economic development, bolster families' economic well-being, and reduce local greenhouse gas emissions. Becoming increasingly concerned that the G-3 was imperiled by decision avoidance psychosis (Tropman, 1997), I proposed to the policy subcommittee that we bring a formal proposal to the next meeting, and adopt the creation of an energy alliance as one of our goals.

\section{AUTHORIZATION TO DEVELOP THE ENERGY ALLIANCE}

At the next meeting of the G-3, the proposal was made to create a program similar to the Cambridge Energy Alliance. The idea was well received, and the group thought it should be included in the G-3's upcoming formal report to the mayor. Furthermore, the committee authorized me to go ahead and pursue development of a local energy alliance independent of the larger G-3 initiative. It was further suggested that I work in conjunction with other local and regional players especially the city's Housing Authority and Urban Development Office, the main utility company for the region, and a local foundation.

On May 16, 2008, I met with administrators at the local Housing Authority and the Office of Urban Development. They were generally supportive, but it was decided to 
postpone further talks until after the June 12, municipal election-from the beginning, the work had an inescapable political component. After the mayor and aforementioned council member were both reelected, a contract was signed on June 27 with the Housing Authority and Office of Urban Development each contributing a modest allocation $(\$ 4,000)$ for an estimated $150-250$ hours toward the development of a feasibility study.

\section{INITIAL ENERGY ALLIANCE PLANNING EFFORTS}

Rothman's (2007) Planned Capacity Development model dictates the need to link efforts to national-level technical assistance and regional players. Rothman (2007) further notes that "interweaving people, economic forces, and ecological protection in a common policy framework" (p. 26) is a hallmark of this model, and these indeed remained the dominant dynamics of the planning phase. Accordingly, I started by contacting a staff member at the Cambridge Energy Alliance; he offered his mentorship, leads for other contacts, and welcomed future assistance if the city made some sort of commitment to the idea. Efforts also included meetings with the only city council member who had served on the original G-3 committee. He suggested a three-step process for moving forward: 1) a feasibility study to determine if an energy alliance would be a viable idea for the city; then, dependent on the outcome of the first step, 2) the design of an organizational structure and development of budgets and funding needs; and, finally 3) the actual creation and implementation of an Energy Alliance.

My next step was to recruit assistance with the writing of the feasibility study. One person that I brought in was a Ph.D. anthropologist with extensive project management expertise who taught at the university's school of business. The other member was a community organizer from Chicago with both grassroots community-level work and professional lobbying experience. The work during this phase was wedded to Rothman's (2007) Planned Capacity Development model with its emphasis on expert-led technical planning to spur development that will both include and benefit more disadvantaged community residents. I felt that this would be the "best fit" for a change effort which required a high level of technical expertise and support from local government officials.

Additionally, within the eight-part community practice model elaborated by Weil and Gamble (2005), early efforts to promote the Energy Alliance could accurately be described as a blend of social planning and community social and economic development. The framework also includes a helpful description of social worker roles; within this iteration of Social Planning, roles consist of and include "researcher," "proposal writer," “communicator," "planner," and "manager" (p. 128). I felt this accurately encapsulated the work up to that point and over the coming months. While the explicit purpose was to determine if an energy alliance was technically, financially, and logistically viable, team members were also aware that the work would need to include public education and promotion efforts akin to a political campaign. The roles of "educator," "promoter," and "negotiator," included under community social and economic development, aptly covered the breadth of roles for team members (Weil \& Gamble, 2005, p. 128). 
Foundational to successful CESD planning is identification of a community need that can be addressed in a way that, in turn, creates a ripple effect of additional improvements (Rubin \& Rubin, 2001; Rubin \& Sherraden, 2005). Similarly, careful planning is key to successful community practice, but a less-mentioned necessary skill is awareness of the larger social and environmental contexts, and how external events may open (or close) windows for action. At the time of the energy alliance's inception, Al Gore's movie, An Inconvenient Truth, was dominating a great deal of discussion across the county. The idea of an energy alliance offered a politically 'soft' approach to concerns about global warming in that everyone could do their part to help reduce carbon emissions--'soft' because it included aspects that could appeal to the array of ideologies dominating the political landscape at that time. For those who accepted the idea of climate change, this was not a difficult sell. For those who did not, we shifted the conversation to being good stewards of the land and the inherent foolishness of wasting resources unnecessarily: Regardless of political inclinations, few tend to support unnecessarily burning resources with no benefit.

On the local level, the release of a report undertaken by another local social worker with sponsorship from the local United Way and other foundations, highlighted the increasingly difficult economic challenges facing the community's low- to moderateincome residents, who were eligible for little or no public assistance, but whose wages had stagnated while facing the state's highest housing costs (Barkdull, 2007). The report made a bit of a stir in the local media and press, and alarmed city officials who did not want to see their community unfavorably compared to others. Timing was good locally to promote the need to make living in the community more affordable; this approach had added appeal by speaking to the need to help individuals who were not able to receive help from often-maligned social programs.

The next event to dominate the headlines came with the approaching heating season. Energy prices began to escalate, and by the middle of that summer the nation was paying an average of $\$ 4.12$ per gallon for regular gas at the pump. In the face of rising fuel costs, both the immediate and long-term benefits of an energy alliance were even more attractive. More efficient homes would immediately result in lower energy bills, and savings would continue to increase if energy prices continued to rise. Furthermore, what had by this time become the feasibility team's proposal could now be explained to conservatives as a mechanism for reducing domestic dependence on foreign oil. This readily enabled the team to build broader support among local elected officials.

As if global climate change and record high oil prices were not enough, 2008 threw yet another crisis at the world in the form of the mortgage crisis in the United States with its ripple effects on the global banking industry and national economies. As we continued to complete the very technical work of the feasibility study, we were also able to point out the value of an energy alliance's promise to create local jobs as unemployed individuals could be trained a hired to weatherize homes.

There were approximately ten thousand homes in our city, and most had been built during or previous to the 1970s; indeed, the housing stock near the city's core was over a century old and had not been adequately rehabbed in relation to energy efficiency. Some 
homes had received a new layer of insulation during the 1970s, but since that time, materials, techniques, and the collective understanding about energy efficiency had all improved. Few local homeowners enjoyed the surplus finances to take advantage of these new technologies, nor did they have the tools or necessary training to do this work themselves.

As noted previously, successful CESD planning is enhanced by identification of a community need that can be addressed in a way that creates a ripple effect of additional improvements (Rubin \& Rubin, 2001; Rubin \& Sherraden, 2005). Our early efforts achieved this objective. Within a brief, 18-month period, we had the exciting prospect of launching an organization that could reduce the economic burden of households with modest incomes, produce good-paying blue collar jobs for the local economy and reduce greenhouse gas emissions-while enjoying broad support across the political spectrum.

The team continued to engage local and elected officials formally and informally, gathering detailed information about the political landscape, and devising promotional appeals that would be effective in neutralizing potential ideological opposition to the effort. Although much of the work on the feasibility study was technical, team members contributed an equal amount of energy and attention to the highly political nature of the enterprise, and the honing of political skills by team members was essential to the early phases of this project. This aspect of local development work is also strongly emphasized by Rubin and Sherraden (2005).

\section{Definition of an Energy Alliance}

At this point it is helpful to briefly offer a description of what an energy alliance is, and how it works, along with the key players and the basic steps. The basic principle of an energy alliance is to make greater use of existing technologies to reduce residential energy use. While factories and SUVs are often the targets of those interested in addressing issues of global climate change, in many communities the greatest consumption of energy takes place in individual homes. In addition to constantly running refrigerators and 'energy vampires' (computers, DVD players, etc), one of the single greatest uses of energy is home heating. All of these can be done more efficiently, and the work to accomplish that generally requires only simple technologies with quickly recouped costs.

More specifically, energy alliances provide a 'one stop shop' resource for homeowners by connecting them to energy audits, trained contractors, and financing. Energy auditors employ various technologies to give homeowners information about the least efficient components of their overall energy system that could be more easily corrected, for the least expense, and with the greatest potential return on dollars invested. Trained contractors then confirm, correct, and add to that information and provide either specific bids for completing necessary work, or advice for do-it-yourself enthusiasts who may want to take on part or all of the work themselves. The combined information from the auditor and the contractor results in various options for making the home more efficient and estimates for projected savings. The resulting energy savings average close to $30 \%$ and the savings immediately offset the costs with total payoff of the original 
investment in as little as two to seven years, after which time the homeowner continues to enjoy savings that increase as energy prices rise. The final step in the energy alliance process is to help make financing arrangements so that the cost can be spread over an appropriate time period with the result that homeowners incur no actual out-of-pocket expense-reductions in utility bills are generally greater than the resulting loan payments. The overall result is that an energy alliance helps connect available technologies and resources with no 'cost' to homeowners while simultaneously reducing carbon emissions. It is a model that is consistent with social work perspectives and benefits from the insights of community development theory.

\section{INTER-ORGANIZATIONAL, MULTIDISCIPLINARY AND CROSS- SECTOR PLANNING}

CESD initiatives require cross-disciplinary and cross-sector collaboration to successfully attend to the myriad of economic, social, and technical details that arise. While Rubin and Sherraden (2005) emphasize this aspect of work at the implementation and management phase, it was equally true in this author's experience during the planning phase. While the three-member feasibility team brought an array of managerial, organizational, interpersonal and political skills to the mix, the list of stakeholders had to be broadened to successfully undertake the feasibility study.

In addition to meeting with auditors, contractors, and bankers, the team met with two different organizations that had already been doing work that overlapped that of the proposed energy alliance: the local Community Action Agency (CAA) and a private business. Both of these entities were critical to helping the team define a more specific focus for the energy alliance, and how it could complement and not duplicate what was already available in the community.

The area CAA runs a weatherization program. Making use of federal funding, they had been retrofitting an average of about 100 homes per year in their four-county area. Their program was similar to an energy alliance in that they began with an audit employing the latest technologies including a blower door and an infrared camera. The blower door is draped across an open, outside door and has a large fan that blows air out of the building. The resulting negative pressure emphasizes any cracks or other weaknesses that might exist around closed windows or doors, and even voids where insulation had slumped inside walls. The infrared camera adds to this by allowing a quick scan of all areas to 'see' where those problems exist, which often include: improperly sealed electrical outlets, cracks around windows and doors, and problems in and around the foundation. These energy efficiency problems too often have no visible evidence and without the combination of the blower door and infrared camera it is unlikely homeowners could finds these weaknesses on their own.

However, the CAA's program is different from the energy alliance model as they only serve those who fall below certain income guidelines - and they offer homeowners little choice. Indeed, spending limits dictate the work that can be completed (the cap of $\$ 3,500$ per home was raised in 2009). Generally speaking, CAA weatherization programs always spend the full amount whether or not it provides the best return on investment, but 
most often, they are not able to spend the necessary amount to address the unique problems of each house. Additionally, they are only able to complete work on a limited number of homes compared to estimates indicating much greater numbers that could benefit.

The team also met with a businessman who had leveraged his sheet metal business and personal relationship with the mayor into contracts with local government to perform audits and upgrades for public buildings. His organization had already enjoyed favorable local press for work on some of the larger city and county buildings. The feasibility study team had originally imagined serving commercial, public, and residential buildings, but became dissuaded as we learned that doing this work with big, non-residential buildings was more complex on several levels. More importantly, the team was not interested in duplicating services or creating unnecessary competition.

The city was already being served by a business addressing large government and commercial buildings, and the CAA weatherization program was serving a modest number of low-income home owners; but neither was set up to serve thousands of middle-income homeowners. Due to the feasibility study team's effective educational and inter-organizational efforts, these stakeholders were supportive of the energy alliance proposal and were convinced that this was a good idea for the city. They saw an energy alliance as an essential service that could reduce the city's carbon output, stem the flow of local dollars to an energy company headquartered in another state, and produce numerous jobs in the local economy.

\section{Completing the Planning Phase}

Based on the responses the team was receiving and the data we were gathering, it seemed increasingly clear that the idea of an energy alliance for our community was viable. However, while auditors, contractors, and banks were already operating in the community in ways that contributed to the overall goals, none of those players could pursue this work unilaterally. And while it all appeared relatively simple, without an energy alliance to coordinate the process, the necessary steps that would result in significant reductions in residential greenhouse gases and the resulting community development were rarely taking place.

Energy audits had been available for years - often for free or at reduced costs - but the few people who took the time to have their homes audited rarely took the next steps: indeed, there was no clear guidance about what those steps might be. Contractors had always been available to do the work, but without the audit and the intervention of an objective third party, many homeowners were unsure about who to hire or about what work to have done. For instance, homeowners could contact a window installer or someone in the business of putting insulation in their attics - and, generally speaking, the contractor was more than happy to sell windows or more insulation-but it was unclear what should be done to assure the most effective changes, in what order, and in what amounts to assure the most favorable ratio of investment to savings.

Without the audit, coordination, and objectivity provided by an energy alliance, the homeowner had little sense of what repairs made the most sense from a financial 
perspective. Finally, without the authority of an energy alliance, financing was rarely available for such endeavors and homeowners were left to invest with insufficient, object information about likely returns. While various tax incentives helped to encourage some improvements for homeowners, these were generally performed in an ad hoc serving the profits of contractors and suppliers. But, without a specific, intentional effort to maximize investments for consumers, the activity was less than it could have been. Ironically, the market-driven system was not serving local business interests or consumers. Very little was being done to reduce carbon emissions

In a similar fashion, the energy alliance model promised to move beyond the tired paradigms of government versus private sector, or Keynesian versus Supply Side economic theories. The government-sponsored weatherization programs carried out by the CAA imposed strict means testing on potential consumers, while the private sector pursued only the most profitable ventures, (generally large commercial buildings over residential dwellings). There was no incentive for either to serve the large number of homes that actually offered the greatest community-wide need, the broadest opportunity for reducing carbon outputs, and the most likely possibility of creating jobs while keeping money in the community.

To fill the gap, the feasibility team proposed a hybrid organization composed of government, private, and non-profit elements as a "one-stop shop." Essentially, local government would house and support a staff person to coordinate the work of energy auditors, local contractors, local banks, and homeowners. Such a position could be sustained with a mix of public sector funding and foundation grants. It was further recommended that the organization be structured as a nimble and flexible social enterprise (Yunus, 2009) that would be mission-driven; its governance structure should carefully ensure cross-sector alignment and accountability (Lawson \& Barkdull, 2001). A CESDO's ability to balance its social mission with business concerns is critical to its viability (Rubin \& Sherraden, 2005).

Our recommendation for launching the energy alliance met no opposition. Instead we received enthusiastic support from the various stakeholders we engaged-from conservative bankers and independent contractors, from visionary energy auditors imagining new ways of meeting energy needs in the most efficient fashion possible, and from homeowners seeking lower energy bills and greater comfort during the long winter.

In August, the team completed an interim report with a clear recommendation for a necessary 'awareness-raising' process - part marketing and part political campaign - to gain support for the idea and to create a sufficient customer base. This report was distributed to all stakeholders including the city. One of the mayor's assistants expressed his appreciation for the interim report, noting that it gave him something concrete to take with him to a meeting in Washington, DC to report on the progress of the city's Cool Cities program.

Work continued on the complete feasibility study with numerous meetings with community groups and government officials. A GANT chart was presented to the mayor's staff demonstrating a carefully coordinated and detailed schedule to secure seed funds and begin pilot projects to test the practical logistics of the model, and to screen 
and hire staff. The feasibility study team had clearly exceeded the original obligation of 150-250 hours in the contract. In October of 2008, a completed feasibility study was distributed to the various city government offices and to local County Commissioners, whose support we had also won.

\section{MOVING FROM PLANNING TO IMPLEMENTATION}

The next stage of the work, accomplished over the next year, took the most time, was the most frustrating, and yielded the fewest gains. A long series of meetings-some involving multiple stakeholders, others limited to direct talks with the mayor's staffresulted in little more than confusion. Through the long winter and spring, the feasibility study team tried to generate support for implementation among city officials who had been beaten down by the vicissitudes of the Fall 2008 elections that swept a number of anti-government Tea Party activists into office locally and nationally. Despite having just won reelection, the mayor's staff felt under attack and was preoccupied with political vulnerability. While the team felt that we were simply asking for permission to write grants on behalf of the city to enter the next phase of the work - the implementation of pilot programs and the initiation of a marketing and education campaign for the public-we instead found ourselves on a treadmill chasing promises. At one point the feasibility study served as the center piece of a 'dog and pony' show for a U.S. Congressman where the city wanted to demonstrate the innovative things it was doing to promote a green economy. Our presentation was rewarded with a high level endorsement from the Congressman's office recommending that the city support our efforts. The city was proud of the endorsement but remained wary of actually taking the necessary steps. Their delaying tactics included repeated requests for additional information that had already been provided, meetings that concluded with vague promises to "move forward," and the absence of decision-makers at crucial junctures.

In the process of gaining cross-sector support, we had failed to manage the relationships as well with the city government - an entity on which we were completely dependent for success. In retrospect, the first two lessons to be taken from the whole experience might be 1) to keep the message simple and clear, and 2) to not become overly dependent on a single course of action. In meetings with the other parties, it was easy to keep the message simple as the focus was on just the portion pertaining to each individual group: Auditors quickly understood what their role would be; contractors were hungry for work; bankers wanted to make loans; homeowners wanted warmer homes and lower energy bills. But in the process of explaining to the city how that would all fit together, the description became more complex. Overworked staff members had not actually read the feasibility study and were unwilling to take the risk of moving forward in what had become a suddenly politically-fraught environment. Values conflicts and misunderstandings are typical challenges in CESD work (Rubin \& Sherraden, 2005), and they increased the very real emotional and physical fatigue of the three feasibility team volunteers.

The team got mired in this unproductive relationship because, for two different reasons, we failed to understand the need to avoid dependence on a single course of action. The first involved the reality that connecting ourselves to the city was the most 
promising place to start, including start-up funds and an office, along with other resources. After all, it was the mayor's office that had initiated our work, even if only indirectly.

The other misunderstanding may have resulted from the fact that none of the feasibility team members was looking for jobs. None of us was interested in actually managing the energy alliance-though we considered ourselves to be the best positioned to get it started-and each of us had other, full-time obligations. Our unwillingness to take a more active role in the implementation phase was a likely concern to the alreadyoverworked city staff and the natural fear that the whole project might land in their laps. Assurance that we would remain involved as citizen volunteers as part of a strong supervisory board (Rubin \& Sherraden, 2005) was a strategy that we thought would prove effective to overcome such concerns, but it was insufficient.

Our dependence on the city's active engagement had hamstrung the initiative at the end of the planning phase. The city was either reluctant or unwilling to make any further commitment at that time, but they kept requesting additional meetings and continued to talk about the Energy Alliance (EA) as though they both supported it and were involved in shepherding its development over the next 6 months.

\section{WINDOW OF OPPORTUNITY, CO-OPTATION, AND DISAPPOINTING RESULTS}

The feasibility study team members had mostly moved on to other projects. As the lead, I continued minimal engagement during this period, until the city received an unexpected boon in the form of American Recovery and Reinvestment Act (ARRA) federal stimulus funds. The mayor's office had applied for and received several hundred thousand dollars in federal, energy efficiency funds. While the ARRA had included additional monies for weatherizing low income housing (and was a fantastic boon to the local Community Action Agency), the ARRA had led to the development of Energy Efficiency and Conservation Block Grants (EECBG), including \$3.1 billion to help states invest in energy efficiency and the green economy. The energy alliance had been one of the major parts of the city's EECBG application. After receiving word that the application had been approved, in May of 2009 the City Council voted to support development of the local energy alliance through an allocation of $\$ 175,000$; further, the new organization would be housed in the Office of Urban Development. The County Commission had also received \$64,000 in EECBG funding, and opted to devote those funds to the effort. Between the two branches of government, the EA now had \$239,000 to implement the new CESDO, only $\$ 3,000$ below what had been recommended for startup in the feasibility study.

According to the plan outlined in the study, the next phase was to include sorting out the various legal issues, developing an accounting process, and creating the necessary boards. I was included as a member of the advisory board, although I was still concerned that the organizational structure for the effort did not resemble the recommendations for the nimble and accountable hybrid organization proposed in the feasibility study. Indeed, what seemed at the time like the long awaited victory turned out to be the beginning of a 
series of disappointments: few of the recommendations in the study were followed; funds were not allocated for the public education campaign or to generate citizen involvement; and the need for twenty-four pilot audits in advance of the 2009 heating seasonessential to the next developmental steps - were essentially ignored.

First, the job search dragged on through the summer months, and as fall approached the city explained that the grant money, though approved, had not yet been released by the federal government. This was discouraging as the city could have provided short-term funding in anticipation of being repaid when the grant finally arrived - certainly, they had sufficient discretionary funds in the spring of 2008 to fund the feasibility study. The window of opportunity to initiate work in advance of the coming heating season was lost.

Near the end of 2009 an individual was hired to serve as the Energy Sustainability Coordinator for the city. While she brought some limited experience necessary for such a role, the breadth of skills needed to accomplish the extremely complex work of starting up and managing the new energy alliance: project management, planning, and development skills, marketing, grassroots citizen involvement, along with personal, political, and inter-organizational skills (Rubin \& Sherraden, 2005)—proved a daunting list. Some health-related problems in the new employee's family further hampered the effort.

There continued to be periodic meetings in which a dwindling number of the same individuals would arrive to rehash matters and to watch the initiative lose momentum. A series of training sessions were made available to create additional auditors, but this contradicted the reality that there was not yet sufficient work for those already trainedoften at their own expense- to do that work. Similarly, contractors were being instructed on matters related to energy efficiency without any corresponding development of a customer base. Bankers were the first to stop coming to the meetings, and-most important of all-there was never any significant presence from homeowners or representatives of neighborhood organizations despite frequent references to long waiting lists of people wanting to make use of the energy alliance's services. Efforts to educate and engage citizens remained minimal.

Over the next two years, only about a dozen homes were audited. Some had repairs completed along with loans from a portion of the original grant to finance the upgrades. At one particularly disappointing meeting, the advisory board was informed that a large portion of the budget was going toward work on public buildings, though the feasibility study had stressed the need to focus on private residences. Indeed, the bulk of the budget was going to the sheet metal business owned by someone with personal connections to an elected city official. At that point it was made explicitly clear that the advisory board was not, in fact, being asked for advice at all, and that the energy alliance had become little more than another layer within the bureaucracy at the Office of Urban Development.

By the end of 2011, the original funding for the energy alliance was mostly spent. While some of that money went into loans to a handful of homeowners, much of it went to pay for a large retrofit of a public building and for two-years of salary for a single job. No meaningful process had been piloted or developed in relation to the energy alliance model. No equipment had been purchased. No extensive public education or marketing 
campaign had been engaged; and visibility is foundational to successful CESD (Rubin \& Sherraden, 2007). Rather than creating a new process to coordinate community resources addressing community needs, and developing a local model for dealing with a global crisis . . \$239,000 in stimulus funding had gone to create a sleepy bureaucratic office and a single job.

In an October 21, 2011 story by Patrick Springer, it was noted that the state where this work had occurred had "finished last among the states in a ranking of progress in striving toward energy efficiency." The same article noted that the state was among "the 10 states 'most in need of improvement (Springer)."' The director of the Great Plains Institute noted that the state stands "out for a lack of leadership (Springer)."

\section{CONCLUSIONS AND CONNECTIONS TO SOCIAL WORK}

Although the tangible results were disappointing in relation to the expectations of the feasibility study and its authors, the fact is that the work had multiple direct and tangential benefits. The efforts to create an energy alliance were central to the city's receipt of EECBG moneys. Fed by those funds the larger, umbrella effort known as the G-3 produced multiple projects that benefitted the city, including traffic light coordination, more efficient public buildings, development of a greenhouse gas inventory (updated annually), an improved recycling program, along with various other projects, awards, and additional EECBG funds. The director that was hired specifically to run the Energy Alliance did not fulfill the hopes outlined in the feasibility study, but she came to be seen as the lead for the G-3 and was able to leverage that work into a job with the state as vice chairwoman of the state chapter of the U.S. Green Building Council.

Utilizing Rubin and Sherraden's concept of CESDOs (Community Economic and Social Development Organizations) helped to benefit the community. The volunteers who participated in this project were successful in creating a new organization within the city government and in procuring Energy Efficiency and Conservation Block Grants. The program did not perform as well as was hoped in relation to providing economic relief for moderate-income families or spurring local economic development, but the energy alliance continues to exist, which may provide an avenue for future change efforts (though it has not had a customer for over a year). The city has also maintained the alliance's website, and support for a more sustainable community is still broad within city government.

There is a widely held misconception that global issues like climate change can only be solved at the international level. While international cooperation may be a necessary component of the multi-layered solutions required, it is a mistake to neglect the need for local action. Furthermore, the reality is that international corporations and treaties, along with national policies have largely been-directly and indirectly-the cause of global climate change. Large governments, corporations, and various international institutions will inevitably seek to protect their interests with the result that, as noted by Rothman (2007), there is always a "danger that the large-scale components will dominate" and that national and even international objectives will receive greater support from institutions such as the World Bank "at the expense of the grassroots component (p. 26)." 
Similar to Rothman's caution above, Kretzmann and McKnight (1993) warn community practitioners about the dangers inherent in handing off grassroots efforts too soon to more-powerful institutions. The efforts to develop a community-focused energy alliance were indeed largely co-opted by the municipal government and its needs, and buffeted by a national election and the chase for federal funds. While aware of this potential danger, volunteers were concerned that to delay further to build and strengthen their grassroots effort would have been too risky; the window of availability to receive federal funds necessary to launch the alliance, and the very short time to react to this unexpected opportunity, seemed more compelling at the time. Issues of timing also played out in the very real (and too frequent) context of volunteer burnout.

The early phases of the energy alliance clearly had compelling ideas, the offer of professional services, and a near abundance (at least according to our budget proposals) of necessary capital. However, most of the other components were largely dependent on the second ingredient - capable leaders. The team had developed a strong base of support during the first phase, but as we handed off the project there was a corresponding decrease in that support. The new director aligned herself with the most immediate dayto-day interests and concerns of her employers in city government rather than the auditors, contractors, bankers, and most importantly the homeowners necessary for an energy alliance. The limited education and marketing efforts engaged by the energy alliance were largely directed by technocrats who did little to go beyond basic messages about the need for energy efficiency-there was no connection to global issues or the possibility of new ways to organize communities. Instead of building a process independent of city government, the energy alliance became part of a perpetual bureaucracy with its inherent tendencies toward self-preservation and limited innovation. As had been anticipated during the writing of the feasibility study, instead of creating jobs, assisting thousands of homeowners, and making a real reduction in greenhouse gas emissions, the city was nominally involved in completing work on little more than a dozen homes - at tremendous relative expense-and then celebrated its success.

Energy alliances offer a model to move beyond the tired paradigms of government versus market forces and offer a promise to meet the "growing need to build human and social capital, develop employment and training opportunities, and ensure basic rights" (Weil \& Gamble, 2005, p. 142). This type of innovative idea represents just one avenue for social work engagement in sustainable community development-an opportunity that Gamble and Hoff (2005) predict will continue to expand over the next two decades or so. Further, they note the unique role that social workers are positioned to play as ethical facilitators and mediators for "citizens forced to choose among competing values and development approaches” (Gamble \& Hoff, 2005, p. 184).

This work had begun with a model deeply embedded in social work values, including efforts "to enhance human well-being" . . . "with particular attention to the needs and empowerment of people who are vulnerable, oppressed, and living in poverty (NASW, 2008, Code of Ethics, Preamble)." Furthermore, it was a model to connect communities around the world. It remains possible that a successful pilot could be replicated in similar communities in the United States, to the north in Canada, and on the other side of the world in China or Bangladesh where increasingly industrialized economies are generating 
growing energy demand, and where the results of climate change are potentially most threatening. It is a model that embraces self-determination and understands that the person exists in their environment, including their social and their physical environment.

This paper began by chiding social workers, especially in the United States, for not paying sufficient attention to environmental issues. The model of coordination and collaboration inherent in an energy alliance offers hope for transforming other aspects of community both on the local and the global level, and a way to operate beyond restrictive paradigms that such work must fall under either government-led efforts or be driven completely by capitalist markets. Social workers have a moral obligation to involve themselves in such work, and to take leadership (Macy \& Brown, 1998; Orr, 1994; Zapf, 2009). What Joanna Macy (Macy \& Brown, 1998) refers to as the 'Great Turning became clear:'

...if there is to be a livable world for those who come after us, it will be because we have managed to make the transition from the Industrial Growth Society to a Life-sustaining Society. When people of the future look back at this historical moment, they will see, perhaps more clearly than we can now, how revolutionary it is (p. 17).

\section{References}

Barkdull, C. (2007). Making ends meet in Grand Forks and East Grand Forks: Are area families working harder? Unpublished manuscript.

Bonzer, M. (2008). Green3 Grand Forks action plan. Retrieved from http://www.grandforksgov.com/Reports/Draft\%20G3\%20Grand\%20Forks\%20Actio n\%20Plan\%20\%280CT\%2008\%29.pdf

Chopra, A. (2009, March 26). How global warming threatens millions in Bangladesh, U.S. News. Retrieved from http://www.usnews.com/news/energy/articles/2009/03/26/how-global-warmingthreatens-millions-in-bangladesh

Gamble, D. N., \& Hoff, M. D. (2005). Sustainable community development. In M. Weil (Ed.), Handbook of community practice (pp. 475-493). Thousand Oaks, CA: Sage Publications, Inc.

Harmeling, S. (2010, December). Global Climate Risk Index 2011: Who suffers most from extreme weather events? Weather-related loss events in 2009 and 1990 to 2009. Retrieved from http://germanwatch.org/de/download/2183.pdf

Kretzmann, J. P., \& McKnight, J. L. (1993). Building communities from the inside out: A path toward finding and mobilizing a community's assets. Evanston, IL: Institute for Policy Research.

Lawson, H., \& Barkdull, C. (2001). Gaining the collaborative advantage and promoting systems and cross-systems change. In A. L. Sallee, H. A. Lawson, \& K. BriarLawson (Eds.), Innovative practices with vulnerable children and families (pp. 245270). Dubuque, IA: Eddie Bowers Publishing, Inc. 
Macy, J., \& Brown, M. Y. (1998). Coming back to life: Practices to reconnect our lives, our world. Gabriola Island, BC, CAN: New Society Publishers.

National Association of Social Workers. (2008). Code of Ethics. Retrieved from http://www.socialworkers.org/pubs/code/code.asp

Orr, D. W. (1994). Earth in mind: On education, environment, and the human prospect. Washington, DC: Island Press.

Rothman, J. (2007). Multi modes of intervention at the macro level. Journal of Community Practice, 15(4), 11-40.

Rubin, H. J., \& Rubin, I. S. (2001). Renewing hope within neighborhoods of despair: The community-based development model. Albany: SUNY Press.

Rubin, H. J., \& Sherraden, M. S. (2005). Community economic and social development. In M. Weil (Ed.), Handbook of community practice (pp. 475-493). Thousand Oaks, CA: Sage Publications, Inc.

Sierra Club. (2011). Solving global warming one city at a time. Retrieved from http://coolcities.us/about.php?sid=c80a9c633df6a1f3b7bbd9de41c64fa1

Springer, P. (2011, October 21). North Dakota gets failing grade for energy efficiency. Grand Forks Herald, p. B1.

Tropman, J. E. (1997). Successful community leadership: A skills guide for volunteers and professionals. Washington, DC: National Association of Social Workers.

United States Conference of Mayors. (2007, June). The United States Conference of Mayors' energy and environment best practices. Retrieved from http://www.usmayors.org/uscm/best_practices/EandEBP07.pdf

University of North Dakota. (2007). 2007 Nobel Peace Prize connects with UND climate scientist. Retrieved from http://www2.und.edu/our/uletterArchive/print_article.php?uletterID=3156

Weil, M., \& Gamble, D. N. (2005). Evolution, models, and the changing context of community practice. In M. Weil (Ed.), Handbook of community practice (pp. 475493). Thousand Oaks, CA: Sage Publications, Inc.

Yunus, M. (2009). Creating a world without poverty: Social business and the future of capitalism. New York: Public Affairs.

Zapf, M. K. (2009). Social work and the environment: Understanding people and place. Toronto, CAN: Canadian Scholars’ Press Inc.

\section{Author note:}

Address correspondence to: Bret A. Weber, PhD, MSW, LCSW, Assistant Professor, Department of Social Work, University of North Dakota, Gillette Hall, Room 109-B, 225 Centennial Dr. Stop 7135, Grand Forks, ND 58202-7135. Email:

bret.weber@email.und.edu 